\title{
Designing and Creating a Game Installation
}

\author{
Matthew Whitby ${ }^{1}$ (D)
}

Received: 28 June 2017/ Accepted: 3 July 2017/Published online: 17 July 2017

(C) The Author(s) 2017. This article is an open access publication

\begin{abstract}
A game installation is a game that incorporates the surrounding environment, something that has mostly been explored on a city-wide scale. This paper concerns the creation of a game installation set within a room, and explores locative media, mixed reality games and the fourth wall. A framework for game installations has been designed and tested with a group of participants in a case study. The results in this paper show that the final artefact could be considered a success; recommendations for deeper development of the framework are also provided.
\end{abstract}

Keywords Art · Installation · Game · Case study and framework

\section{Introduction}

An art installation comprises "mixed-media constructions or assemblages usually designed for a specific place and for a temporary period of time" (Tate Modern 2016). More commonly, this is done through traditional artistic mediums, including standard canvases, sculptures, photography and sometimes film.

One of the most notorious art installations is Tracey Emin's My Bed (1998). Tracey Emin found a way to tell a story through presenting her own bed: the little details scattered around the scene give small glimpses into her life. According to the Saatchi Gallery (2016), "By presenting her bed as art, Tracey Emin shares her most personal space, revealing she is as insecure and imperfect as the rest of the world." Art installations often involve putting something on display, although they might also include huge creations and even entire rooms. One example is Yayio Kusama's The Obliteration Room (2011), which features an entire white room where visitors

Matthew Whitby

matthew.whitby@myport.ac.uk

1 University of Portsmouth, Winston Churchill Avenue, Portsmouth, UK 
are given a sheet of coloured sticker dots to place around the room however they desire. The entire art installation is collaborative and interactive; the scope of the piece can be seen through the lens of a game:

The white room is gradually obliterated over the course of the exhibition, the space changing measurably with the passage of time as the dots accumulate as a result of thousands and thousands of collaborators. (Kusama 2015).

Art installations, unlike more traditional art mediums, can allow for observers' participation, and it is through such interaction where their uniqueness thrives. As an extension of physical art installations, there are also a growing number of digital art installations with a focus on interactivity. Digital art is defined by Christiane Paul (2015), curator of the Whitney Museum of American Art, as "a general term for a range of artistic works and practices that use digital technology as an essential part of the creative and/or presentation process". Thus, the focus of any digital art installation is to incorporate digital works within the real world. Examples include Michael Takeo Magruder's De/coding the Apocalypse (2014) in which he digitalised aspects of The Book of Revelation from the Bible; and, Carina Ow's Plane White (2011), which was an interactive wall that would reveal an artistic background when touched.

Digital artefacts (including games) however are becoming a more frequent sight within exhibitions. Scott Snibbe, for example, works to create whole spaces of digital art. According to Danielle Thom (2014) of Apollo Magazine, "Often on a monumental scale, and installed in public spaces, these experiential works draw in a wide, sometimes unsuspecting audience." The focus of this paper, however, is not the place games have within art exhibitions, but on the design process of knowing where the player will be in order to subvert players' expectations and create new experiences.

Locative media is a common name for any media bound to a location. The term was originally coined by Karlis Kalnins to describe processes and products out of the Locative Media Lab (Galloway and Ward 2007, p. 3). The definition is shifted when the concept of locative games is introduced: Mary Flanagan (2009, p197) stated, "Locative games offer an ambiguous or ambient game experience. Players explore ideas of participation and space particularly the space of the city, by combining physical and technological play."

On a smaller scale, there have been games like Lie to the Devil (produced by Jonathan Zungre in 2014), which, according to Zungre, can only be played under certain conditions: "Here's the setup: you enter a dark room and sit at a desk before a laptop while a crowd watches you through a large windowpane." (Johnson 2014). Inside Lie to the Devil, players use a computer to speak to an AI, which will eventually attempt to convince the player to shoot themselves. Zungre stated: "I wanted it to feel weird and dangerous, with real-world consequences." The realworld consequences are where the digital game overlaps with the real world, despite raising some ethical issues.

There are numerous examples of real world spaces being turned into whole game installations. $S F 0$, for example, is a website that offers users daily challenges to engage in the real world, rewarding points for each task completed. Steve Symons' Aura (2004) was an interactive sound installation based on GPS: users would search 
around, and receive certain sound cues as they reached different locations. Pokémon Go (Niantic 2016) is a prime example of a modern locative game, where players are actively rewarded for going to set locations and interacting with their surrounding environment.

There is a small line between the artefact being defined as a locative media game or a mixed reality game. Mixed reality is not about being bound to a location, but to "deliberately disrupt the conventional definitions of player, play session and play space" (Flintham 2012). The moment the player cannot identify where the game stops is exactly where the game's reality mixes with the real world.

The introduction of webcams for consoles allowed users to turn their living rooms into play spaces; these devices have been adapted, with improvements in camera quality and facial scanning. Microsoft's RoomAlive is, according to Microsoft (2014), "A proof-of-concept prototype that transforms any room into an immersive, augmented, magically entertainment experience." Technology has continued to push when and where locative games can appear, even expanding into people's homes.

The Train (2009) was an experience created by Brenda Romero in which players, through the means of a board game, transported pieces from one side of the train track to the other, only to discover at the end that it was representative of concentration camps during the Second World War. The moment the player realises that the game is a metaphor, their understanding of the experience changes.

Video games that are self-aware of their medium often break what is termed 'the fourth wall'. Elizabeth Bell (2008, p203) defined this as "an imaginary barrier between the characters and the audience". These have produced iconic moments in gaming where the player is forced to do something unexpected. Metal Gear Solid (Konami Computer Entertainment 1998) had one boss that could only be defeated if the player unplugged their controller and moved it into the second slot; before then, it was unheard of for the player to have to engage physically with their console in order to solve an in-game challenge. When playing StarTropics (Nintendo IRD 1990), players have to submerge a physical piece of paper underwater to reveal a secret message. It is these sorts of experiences which, although they are on a smaller scale to full art installations, still have significant impact and lasting impressions on the players themselves. Another fourth wall-breaking puzzle is Eternal Darkness: Sanity's Requiem (Silicon Knights 2002), in which there are fake glitches, such as the volume being muted, the TV turning off, or the player's saved progress being deleted; these affect the in-game sanity meter, which induces a sense of panic among players.

The idea of real world puzzles has been explored widely, and even commercialised as escape rooms. According to Curious Escape (2016), "Escape rooms are fun puzzle rooms in which a group of people are locked into a room and need to solve a series of puzzles to escape before the time runs out!" Players interact with their environment or work as a team, finding items hidden with clues. One such pursuit is geocaching, which takes place in pre-designed sets and which emanate game installations. Geocaching puzzles range from finding hidden keys to decrypting codes. 
As stated, a purpose of a game installation artefact is to subvert the player's expectations. As Davey Wrenden, who worked on Stanley Parable (Galactic Café 2013), describes: "People build up these little tepees - these preconceived ideas about games - where they feel safe. But we don't even know what games are or can be! This is the game fighting back, knocking those ideas down, responding to how you play. That's your mirror." (Wrenden 2013).

Such an artefact is intended to be a piece of art that showcases, and reveals the implications of, a game installation/locative game. Players are fooled into believing it is another digital game, only to discover that the game includes their surrounding environment. The type of research required for this is "research where the product is an artefact - where the thinking is, so to speak, embodied in the artefact" (Frayling 1994, p 8).

In this design process research, the focus of the artefact is shifted onto what it is meant to represent. Peter Lunenfield (2003) supported Fraying's definition with this statement: "Research for design is the hardest to characterise as its purpose is to create objects and systems that display the results of the research and prove its worth." The product should allow players to come away thinking of all the ways the experience was shaped for them.

\section{Establishing a Framework}

An Interactive Art Framework has been developed, and is illustrated in Fig. 1. The purpose of this framework is to outline where all the current forms of interactive art fall in comparison to one another. The primary foci for each medium are its

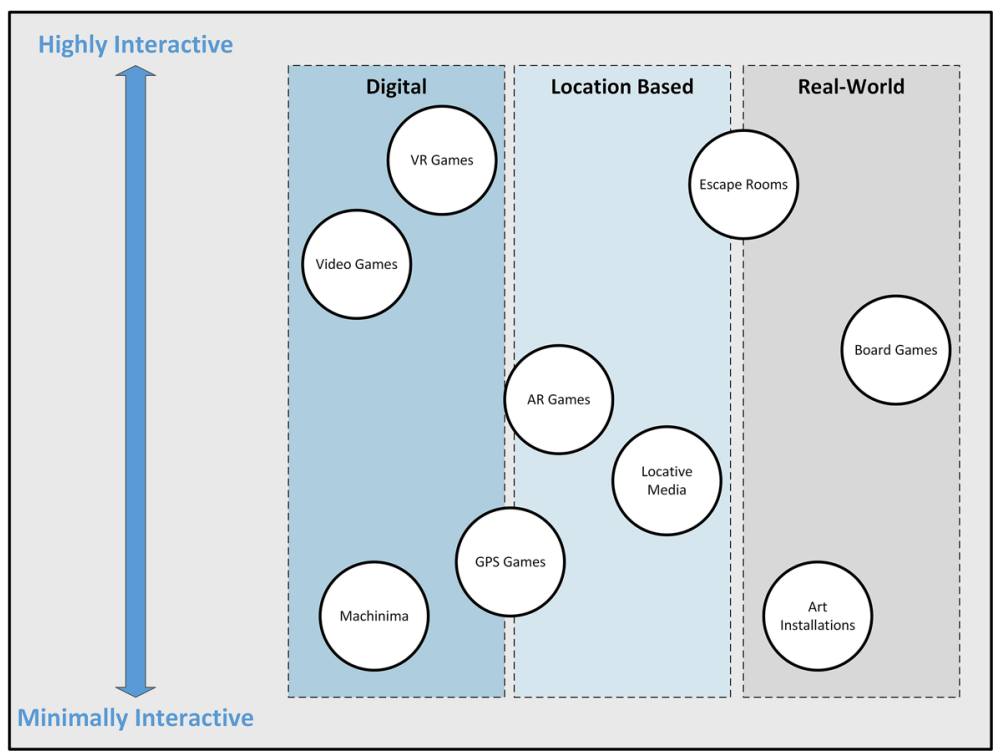

Fig. 1 Game installation framework 
interactivity, and the balance set between the digital and real worlds. It should be noted, for the sake of argument, that video games and similar mediums are a considered a form of art within this artefact. As shown in Fig. 1, the final proposed framework encapsulates all the types of art installations and games discussed in the previous section. These fall into three distinct categories: digital, location-based and real world-based. The positioning of each medium is based on its interactivity (the variable on the $\mathrm{Y}$ axis). Mediums that share features of more than one category include escape rooms and AR games.

The purpose of the created framework is to contextualize the empty areas of the framework where there is potential of breaking new ground in game installation design. The framework can be expanded in the future to cover areas beyond the scope of the artefact described in this paper, and to account for advancing technologies. This conceptual framework has also been tested and validated in a case study. A fairly empty region inside the framework was identified (Fig. 2); and, in the case study, participants were asked to experience and reflect upon the functionality of the presented framework.

One of the objectives of the case study was to explore spaces within the established framework. There are some mediums that belong in two categories, but there are none that incorporate all three while remaining highly interactive.

There have been examples of digital and real-world mediums that are locationbased; however, to date there have been no successful game installations that combine digital and real-world features and which are location-based. It was anticipated that placing the case study installation in the position within the framework shown in Fig. 2 would lead to some interesting, unique results. The

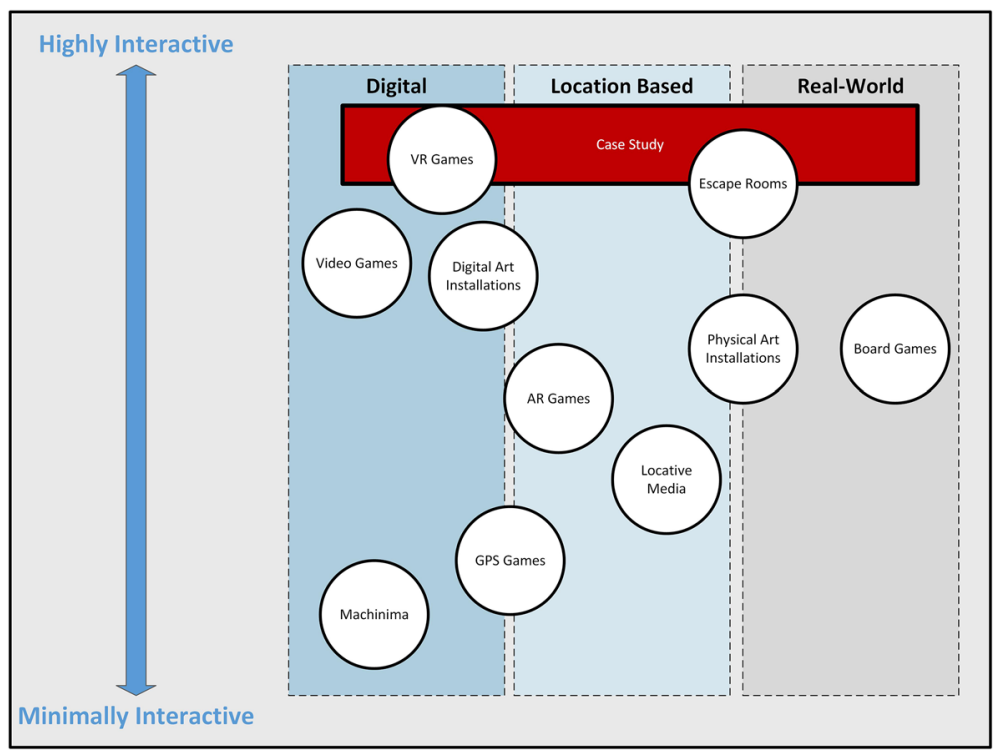

Fig. 2 Positioning of the case study's game installation in the framework 
purpose was to create a video game installation, which by its nature is interactive, hence why it is placed towards the top of the framework.

\section{Aims and Objectives of the Case Study}

The aim of the case study was to explore how users react to the sort of game installation outlined in Fig. 2, and to record their emotions during gameplay. There were four objectives to the case study:

1. A total of 20 participants were invited to experience the game installation, and were then interviewed about their experiences and opinions of the game installation;

2. The participants' views on environmental interactions were documented;

3. The particpants were asked to evaluate whether the game installation was enjoyable; and,

4. The framework was also evaluated for feasibility.

\section{Methods}

Convenience sampling was used for the case study: only people who lived locally and who had easy access to the game installation were targeted. For every participant, the same interview format and questions were used. All participants consented to participating in the game installation and being interviewed, and were permitted to withdraw from the case study at any time. Before offering their consent, each participant was informed about the purpose of the case study, and that they would be asked to participate in the game installation and subsequent interview. Data gathered during the interviews was then processed using thematic analysis in order to identify common issues (Bricki 2007), which were then grouped into themes relevant to the aim and objectives of the case study.

\subsection{Design}

The case study commenced with a short experience, during which the players (participants) assumed two roles. The first is a character within the digital environment; after a little while, it was revealed to them that they were also a second character inside the real world. It was anticipated that, as soon as the players were informed about the second character, they became more immersed.

The game itself was a spy/espionage setting, and so the actions that the players performed were synonymous with those of a spy. This was designed purposefully in order to avoid thematical disconnect: logically, it makes sense for someone to have to sneak into another office to help an agent out in the field.

The digital component was acting as a field agent sneaking into the head office of someone important. Each player had to sneak past security guards, bypass all the 
firewalls, and enter passwords to crack into a safe. The passwords required had to be supplied by another agent, and this communication took place in an actual office where each user had to play the game.

At this stage of the game, each player had to physically search around their surroundings to find passwords/information, and switch between playing inside real and digital environments. The participants completed a series of puzzles, in which there were different forms of interactions.

\subsection{Creation}

The case study was conducted using a PC with an Intel Core $17-4820 \mathrm{~K}$ processor, 16 GB of RAM, and NVIDA GeForce GTX 660 graphics card, all running on Windows 7 64-bit. All software packages and hardward required for the case study are listed in Tables 1 and 2:

\subsection{Questionnaire and Interview}

The participants were also asked to complete a questionnaire, which contained six questions; for each one, they had to rate a certain aspect of the game installation from 1 ("not at all") to 10 ("absolutely"):

Q1 On a scale of 1 to 10 , how much did you enjoy the experience?

Q2 On a scale of 1 to 10 , how surprised were you by the reveal?

Q3 On a scale of 1 to 10 , how immersed did you find yourself?

Q4 On a scale of 1 to 10 , how interactive did the game feel?

Q5 On a scale of 1 to 10 , how difficult did you find the game?

Q6 On a scale of 1 to 10 , how stressful did you find the experience?

In addition, each participant was interviewed on their views of the game installation experience, the game's characters and the merging of the digital and real worlds in the game.

Table 1 Software packages used for the case study

\begin{tabular}{ll}
\hline Software package & Justification \\
\hline Unity & Personal experience working with this game engine \\
Adobe photoshop CC 2015 & Ease of use \\
Blender & Personal experience of using this package. \\
Substance painter 2 & Personal experience, ease of use \\
Microsoft visual studios & Ease of use \\
Fraps & Gameplay recording. Ease of use \\
Sound recorder & Personal preference, ease of use \\
Audacity & Audio file editing \\
NVivo & A simple method of combing and sorting through all the data gathered \\
\hline
\end{tabular}


Table 2 Hardware used for the case study

\begin{tabular}{ll}
\hline Hardware Required & Justification \\
\hline Microphone & Recording end user feedback \\
Keyboard and Mouse & Players had to use these devices during the game \\
Case study computer & Used during the case study \\
USB button & Possibly required for the artefact \\
Tablet device & A device for the participants to carry out the survey portion of the case study \\
Handheld camera & Recording the participants' activities during the experiment \\
\hline
\end{tabular}

\subsection{Experimentation}

The game installation was established within one of the office rooms within The Eldon Building at The University of Portsmouth. The room was selected for the purpose of thematic cohesion between the digital game and the real world. A total of 20 unique experiments were completed in three days (14, 21 and 24 February 2017).

\section{Results}

\subsection{Case Study}

\subsubsection{Participant Reactions}

There were some interesting reactions from the participants when they were informed that they also had to operate in the real physical world in order to complete the game. Some participants turned around and asked if they could get up and search around the designated room. They all appeared to be surprised at the prospect of having to interact with something outside digital space. A few of them laughed, probably because they experienced pleasant surprise. A few other participants appeared confused while they attempted to solve the puzzles. In extreme cases, outside help was required to ensure that they could complete the case study.

\subsubsection{Environment}

It should be noted that the participants were enrolled at The University of Portsmouth; some of them had even entered the office room before, and so were able to identify misplaced objects more easily.

\subsubsection{Issues}

There were two instances when a participant required additional help to complete the case study. One arose due to a minor software bug: this problem was resolved quickly as the participant was familiar with similar experiences and logic-based 
puzzles. In the other instance, a participant needed clarification on how to solve the puzzle. It was agreed prior to experimentation that assistance would be provided to participants who struggled to comprehend the rules of the game.

\subsection{Interview Questions}

There were some stages during the interview where additional questions needed to be asked in order to clarify the participants' opinions. When asked if they believe the game installation to be a piece of art, some participants were hesitant. They found the question difficult to answer, either because the question itself is subjective, or because the question needed to be focused on specific aspects such as commercial value or the 'games as art' concept.

Nevertheless, the interviews were completed successfully without any significant problems. Participants were told when the recording began, and the questions were asked in the following order:

1. How did you feel about the reveal of having to interact with the surrounding environment?

2. Did any of the interactions make you feel uncomfortable at all?

3. How did you feel about the merge between the digital and real world?

4. How immersive did you find the whole experience?

5. Did you feel any connection to the character you were playing as?

6. How did you feel about the ending?

7. Would you like to experience a more developed game?

8. Did you have any issues with the game itself?

9. Would you call what you played a piece of art?

The order was carefully designed so that the questions naturally flowed from one to the next, with each question being focused on a particular theme. The first three questions concern interactions between the real world and the digital world. Questions 4, 5 and 6 are about immersion, the narrative and storyline of the game installation. The information provided in answer to questions 7 and 8 might benefit future developments. The last question is arguably the most subjective: participants struggled with framing this question, but the intention behind this question was to link participants' opinions with the concepts of art installations discussed back in Sect. 1. Some participants were asked follow-up questions, whereby they were asked to expand on their arguments or provide further comments. Each interview lasted between four and ten minutes.

\section{Discussion}

\subsection{Coding Analysis}

The data collected from the interviews was subject to two coding analysis phases. For each interview transcript, the first coding analysis was completed on the same 
day of the interview. During the first coding analysis, the data was categorised into broad themes; in the second coding analysis, specific sub-themes were identified. The second coding phase covered every previously coded node, whereby each subject was broken down into further sub-nodes. Some of the themes dissected are illustrated in Fig. 3. This coding analysis method using NVivo makes analysis of recurring themes significantly easier. For each node, the findings from the interviews were summarized so that comments were not repeated.

\begin{tabular}{|c|c|c|c|}
\hline \multicolumn{4}{|l|}{ Nodes } \\
\hline Name & , 祭 & Sources & References \\
\hline$\Theta \bigcirc A r t$ & & 17 & 21 \\
\hline A_GameVisuals & & 3 & 3 \\
\hline A_lsart & & 10 & 10 \\
\hline - A_lsExperience & & 4 & 4 \\
\hline A_NotArt & & 4 & 4 \\
\hline - A_References & & 3 & 4 \\
\hline$\boxminus \bigcirc$ Characters & & 15 & 18 \\
\hline C_CharacterDivide & & 5 & 6 \\
\hline - C_MultipleCharacters & & 5 & 5 \\
\hline L C_Narrator & & 5 & 6 \\
\hline$\Theta \bigcirc$ Ending & & 19 & 23 \\
\hline EN_Expected & & 2 & 2 \\
\hline - EN_funny & & 4 & 4 \\
\hline - EN_Mistake & & 5 & 5 \\
\hline L EN_Surprised & & 14 & 14 \\
\hline$\boxminus \bigcirc$ Environment & & 17 & 28 \\
\hline ENV_Digital & & 4 & 4 \\
\hline ENV_Interactions & & 12 & 14 \\
\hline ENV_References & & 5 & 5 \\
\hline ENV_SetUp & & 3 & 4 \\
\hline$\theta \bigcirc$ Immersion & & 19 & 25 \\
\hline IM_Character & & 5 & 5 \\
\hline IM_Confirmed & & 13 & 14 \\
\hline IM_Conflicting & & 1 & 1 \\
\hline IM_Mild & & 3 & 3 \\
\hline E. Improvements & & 19 & 32 \\
\hline - IMP_Audio & & 3 & 3 \\
\hline - IMP_Controls & & 7 & 7 \\
\hline - IMP_Directions & & 1 & 1 \\
\hline IMP_Ending & & 2 & 2 \\
\hline -OIMP_Graphics & & 1 & 1 \\
\hline
\end{tabular}

Fig. 3 Second coding phase nodes (produced using NVivo) 


\subsection{Discussion}

\subsubsection{The Moment When Participants Realized They Had to Complete the Game in Both Digital and Real Worlds}

Prior to the experiment, the participants were not informed that the game would expand beyond the computer screen; this information came as unexpected news in the midst of the game. For some, this came as a pleasant surprise:

I wasn't expecting it, which was quite nice to be honest. (Participant 1).

Because I wasn't expecting it, it was very strange because I was looking within the game for the answers, when actually the answers were right in front of me on the desk. Which is pretty crazy. So...I liked it. (Participant 12). It was a little surprising at first, but I felt it was OK...Brilliant. Right. (Participant 4).

It was unexpected, but I liked it. It's unusual to get that in games. (Participant 6).

However, two participants, both of whom had been in the office room before, had hitherto suspected that the game involved the room itself:

I saw it coming because of the post-it note on the screen... It helped that this is Rod's office. I've been here a few times. (Participant 9).

In all honesty, the first time I entered the room the first thing I took notice of was the piece of paper [with] the computer password. And after that, he wants me to put in a password, so that's probably it. (Participant 16).

The post-it note interaction was designed to grab the participants' attention and make them feel at ease when they found out that they had to interact with the real world as well as the digital world. However, this was not the experience of participants who had previously visited the office room. Were this experiment to be repeated in future, only participants who are unfamiliar with the designated room should be selected.

The only negative remark made was one concerning the limitations of the game installation:

I thought it was...creative, but it was actually limited in terms of when and where you can play it. (Participant 2).

This was expected since a game installation is a locative medium, a pervasive game that is restricted in terms of location.

\subsubsection{Feelings of Discomfort}

The entire surrounding environment was an academic's office, filled with all his personal effects and documents. Five participants felt that they were intruding whenever they were searching through the academic's personal belongings. Three of them commented: 
Yes, going through his own cupboards felt a little naughty. Yes, that felt a little invasive. (Participant 13).

So, looking through peoples filing cabinets that feels a bit weird to me. (Participant 14).

I felt a bit bad going through someone else's stuff. (Participant 17).

In the game's plot, the participants had to act as secret agents, and so such feelings were expected to increase their sense of immersion. One participant (Participant 12) actually experienced physical discomfort, although this is because he had to walk using a cane, and so had to stand and sit. Another participant felt anxious after taking the wrong approach to the game:

...Because I was rushing it. I thought I'd be dead clever. (Participant 3).

The puzzles inside the real world involved interacting with different objects around the office room: for the average video games player, this sort of interaction with games is uncommon. So, it should have been expected that a few participants felt uncomfortable:

[I felt uncomfortable with] the last task of quickly looking for the book, but apart from that the game was all really good. (Participant 11).

I kept thinking to myself, 'I'm looking around this guy's desk.' (Participant 4). ...Having to do something a bit different, a bit weird, threw me off slightly. (Participant 8).

Nevertheless, all the participants managed to complete the puzzles and perform the necessary interactions.

One participant found the experience of being watched during the case study unsettling:

And because you're there, I kept thinking to myself, 'Am I doing something stupid?' (Participant 1).

However, it was necessary for each participant to be supervised, just in case he or she needed assistance.

Two participants said that none of the interactions made them feel uncomfortable, which might be a taken as a compliment for the game installation. The aim of the game itself was not specifically to make participants feel uncomfortable, although the puzzle solving and environment was designed to make them more alert.

Four participants in total felt unsure about what they were required to do in the game. According to two of them:

I didn't know if I was doing the right thing. (Participant 1).

All of them. Only because of not knowing." "I kept thinking, 'What if I can't

find the thing?' But otherwise, I didn't feel uncomfortable... (Participant 7).

However, some participants enjoyed the sense of uncertainty and feeling uncomfortable. According to Participant 9: 
...I've done those 'escape room' [games] before, and that's fine when you know when you're going to do it. I think it was a bit weird because it was a surprise but it was kinda nice. I like those kinds of games when they do that.

\subsubsection{Enjoyment}

One of the most enjoyable aspects of the game installation was the moment when participants were informed that the game extended into the real world. In total, 15 participants found this satisfying. According to three of them:

I really liked it. It's quite unusual in games, but I feel like it makes the user more involved. (Participant 6).

To start off with, obviously, I was taken aback because it's not something I was accustomed to; but, once I...searched around the desk and stuff a few times it became quite seamless. (Participant 12).

I liked it; I thought it was quite nice. I noticed that once you stepped into the office that it's actually a representation of the office. (Participant 13).

Given that one of the objectives of this case study was to investigate how players react to a change in game boundaries, it is encouraging to note that most players enjoyed that experience. When asked how they felt when they were informed that the game involved searching for items in a physical office room, three participants remarked:

Ah! It was really cool. It's a nice touch... (Participant 13).

I thought that it was one of the best bits of [the game]. (Participant 2).

It was interesting and unique. I quite enjoyed it. (Participant 7).

Five participants said they enjoyed the interactions in the game. According to two of them:

It was good, I personally quite enjoyed it. Because I quite like interacting with things. (Participant 1).

...I do like that interaction. It went above and beyond a normal game. (Participant 11).

\subsubsection{Immersion}

Although there exist official definitions of immersion, different people hold different opinions as to what immersion is. One participant commented that there were two different forms of immersion during game play:

When I get immersed in a game...the monitor becomes my reality rather than this [the real world]...But from the viewpoint of that I'm actually playing the game here [in the real world], it was very immersive in that sense...you get the cut-off point when that isn't you in there [in the digital world], so then you're not that immersed... and this conflicts with the immersion you're used to... (Participant 14). 
This 'cut-off point', of feeling immersed with two characters simultaneously, is worth investigating further. In the game installation, participants who became immersed considered themselves one with 'Agent B', the real-world character; defining this "new immersion" could yield interesting results. Many of the participants experienced a sense of immersion when completing the game:

Later on when I knew what I was doing, it was quite immersive. (Participant 1).

A lot more than I was expecting it to be, it's not quite VR. But it's probably up there. (Participant 12).

To the point of virtual reality, if not more immersive than that. Because there is a merge; there is a blur between what is real and not real. (Participant 13). I would say that there wasn't anything that wasn't immersive. (Participant 7).

From these statements alone, it may be concluded that the game installation contained immersive elements. However, since the sample size in this case study is small, further investigation is needed to confirm this. Not every participant in this study felt strongly immersed in the game. According to two participants:

It was not super-immersive, but...there was a feeling of immersion. (Participant 15).

Not super-immersive if I'm honest because, obviously, I didn't find the art style that immersive. (Participant 19).

Immersion is a subjective concept; however, only 3 (15\% of) participants found the game to be strongly immersive. Participant 13 remarked that the game became more compelling once the real-world interactions began:

The second you start interacting with things in your world to then influence the virtual world, I think it becomes very immersive to the point of virtual reality. If not, more immersive than that. (Participant 13).

Feeling a connection to any character can sometimes lead to deeper levels of immersion, although this depends on how players perceive the characters or themselves. Among the five participants who commented on their sense of immersion in relation to the game characters, two sub-themes arose. The first was deeper immersion after some reflection; when the participants thought more about the characters, they felt a stronger connection. According to two participants:

At first I wasn't sure, but then I understood that I was, physically, Agent B, even though I was playing Agent A. And they were two separate characters, I guess that was an interesting take on it. (Participant 18).

Maybe not straight away, but I began to think about it. At the time, I was just...doing what I was told. But like the more you think about it, that's actually really cool. (Participant 3).

Another sub-theme was the ability to identify and separate between a real-world and virtual character. Overall, participants' views on this were positive. According to Participant 2: 
It's good. I like how the person you're playing in the game is one character and you outside are meant to be a different character.

\subsubsection{Game Ending}

The game had a sudden and surprising ending, a bomb explosion, which caught a few participants off guard. Comments from the participants on the game ending were grouped under the "Surprised node". Four participants also found the ending to be humorous. According to one of them:

That was very good. Very cheeky. It reminded me of Stanley Parable at lot as well, so trying to fool you into certain things and then literally blowing up in your face. (Participant 13).

Despite this not being intended for the game installation, certain aspects such as the narrator's voice or props had comical elements, so this could have been predicted. Humor is not considered a negative emotion, and it would be interesting to explore comedy within game installations in future research.

From a large portion of responses, fourteen in total, it was clear that the participants were surprised at the bomb going off. Most participants spoke about this surprise in a positive light. According to two of them:

It was...clever because of the way it was phrased...you would assume if you pushed the button it would stop the bomb, but then it didn't. (Participant 6).

This guy (the narrator) has told you what to do and each time it's been correct and you should listen to him. And then he tells you to push the button and you panic...it was building up to this point well, to then there's the flip. (Participant 17).

Two participants actually managed to predict the ending before it happened. One of them had previously been aware of the project, and wanted to participate. The other, however, picked up subtle hints that were placed throughout the game:

Heavily hinted towards the ending with all the props. I did mention that it looked very suspicious with the double-cross being the password. (Participant $5)$.

However, five participants felt that they had made a mistake, as the bomb exploded due to their input. According to two participants:

I felt unsure because it told me to push the red button and it blew up anyway. (Participant 20).

It was very abrupt. Not really sure what was going on. I assumed there was more, so I pushed the button and I didn't get to hear what he said. (Participant 7).

In view of these remarks, perhaps the narrative in the game could be changed so that participants would know exactly what their input would cause. One participant even suggested leaving a notice alongside the bomb that reads, "It's a trap." 
Nevertheless, it is encouraging to note that some participants picked up on the subtle hints that were weaved through some of the prop design and which added to the game's narrative.

Participant 12 accepted the ending, and considered it to be suitable: "It's a bit abrupt, but everything has to end at some point." The abrupt ending with the bomb explosion was intended to surprise the participants; in that respect, the game installation was a success.

\subsubsection{Game Characters}

As mentioned, the participants assumed the role of two characters: one in the digital world, and the other in the real world. The character divide was an interesting topic to explore with the participants, whose reactions to this varied. The issue surrounding the divide is best summarized here:

It's hard to say because you are role-playing as two different people and not in the conventional way. (Participant 2).

Three more outstanding statements are worthy of consideration:

No. I didn't see them as separate characters: I saw them as me in different worlds. (Participant 13).

This highlights a good level of immersion, of the participant believing oneself to be the real and virtual characters, simultaneously.

Even when I was looking around the room, I felt that it wasn't me. Well, it's not something I would normally do. The game was instructing me to do it, so again I'm a video game character at that point. (Participant 14).

This sort of connection relates to escape rooms or immersive theatre, where players take on the role of a character; user self-disconnection could be another fascinating topic worth exploring in further research.

The third comment shown below includes a recommendation for the characters, Agent A and Agent B, which exist separately from each other (in the virtual world and real world):

I feel there is a slight disconnection between the two... If the narrator is referring to the same person it might make more sense. But the game is still fairly good. (Participant 16).

Nevertheless, most participants found the separation to be enjoyable.

Two participants both commented on the ease of feeling immersed with Agent B, simply because they were themselves:

There was the character I was controlling and then I was the other character it was talking about. So, it was making me a character. Do I feel like me? (Participant 10).

I got more immersed into that character, because it was me. [Laughs] First one less so. (Participant 8). 
It was pleasing to hear participants talk excitingly about how immersed they felt at certain points of the game; it was evident that the separation of the two characters between the virtual and real worlds was a good idea. According to two other participants:

So I was basically controlling Character One in the game and I myself was Character Two in the real-world game. (Participant 17).

I felt more involved with them and more like I was acting in the role of one of them, more so than just sitting and playing. (Participant 6).

The purpose of the narrator was to guide each participant through each interaction to complete the game. Of the six references to the narrator in the interview transcripts, all except one were positive. Positive comments included:

...I don't know if you've ever played 'The Stanley Parable'? So when I heard the narrator's voice, it was an instant reminder. Really well done, really well presented. (Participant 11).

The voice acting made it good. (Participant 17).

I felt connected to the voice that was speaking to me. (Participant 4).

It should be mentioned that the voice actor hired for this project did a good job of reading the voice-over lines. Only Participant 19 was critical:

It's a sort of Archer-style voiceover, so it's not really something I can relate to...I just thought it was rather comical.

This remark is probably no more than a reflection of personal preference.

Overall, there were three critical revelations in the game: the fact that the game crosses the border between the virtual world and the real world; the fact that each of the two characters occupies one of these worlds; and, the unintuitive bomb detonation ending.

Only one participant made any direct reference to the revelation about the two characters:

I'm used to playing games in which I'm the guy on the screen; I thought that maybe I'm Agent B. I felt strange knowing I'm not this guy here, that I'm just looking at and watching him. (Participant 14).

\subsubsection{Interaction}

Four participants voiced feelings of discomfort, or believed their actions to be invasive. This is due to the nature of some of the puzzles, which involved searching through someone's real office:

Going through his cupboards felt a little naughty. Yeah, that felt a little invasive. (Participant 13).

Looking through people's filing cabinets - that feels a bit weird to me. (Participant 14). 
Table 3 Questionnaire results ( $1=$ "not at all", $10=$ "absolutely")

\begin{tabular}{|c|c|c|c|c|c|c|}
\hline & $\begin{array}{l}\text { Q1: On a } \\
\text { scale of } 1 \text { to } \\
10, \text { how } \\
\text { much did } \\
\text { you enjoy } \\
\text { the } \\
\text { experience? }\end{array}$ & $\begin{array}{l}\text { Q2: On a scale of } \\
1 \text { to } 10 \text {, how } \\
\text { surprised were } \\
\text { you when you } \\
\text { found that the } \\
\text { game extended } \\
\text { into the real } \\
\text { world? }\end{array}$ & $\begin{array}{l}\text { Q3: On a } \\
\text { scale of } 1 \\
\text { to } 10 \text {, how } \\
\text { immersed } \\
\text { did you } \\
\text { find } \\
\text { yourself? }\end{array}$ & $\begin{array}{l}\text { Q4: On a } \\
\text { scale of } 1 \text { to } \\
10 \text {, how } \\
\text { interactive } \\
\text { do you think } \\
\text { the game } \\
\text { was? }\end{array}$ & $\begin{array}{l}\text { Q5: On a } \\
\text { scale of } 1 \\
\text { to } 10, \text { how } \\
\text { difficult } \\
\text { did you } \\
\text { find the } \\
\text { game? }\end{array}$ & $\begin{array}{l}\text { Q6: On a } \\
\text { scale of } 1 \text { to } \\
10, \text { how } \\
\text { stressful did } \\
\text { you find the } \\
\text { experience? }\end{array}$ \\
\hline \multicolumn{7}{|c|}{ Participant } \\
\hline 1 & 9 & 7 & 8 & 10 & 5 & 3 \\
\hline 2 & 10 & 10 & 10 & 10 & 8 & 1 \\
\hline 3 & 8 & 10 & 9 & 8 & 5 & 3 \\
\hline 4 & 8 & 8 & 7 & 8 & 4 & 4 \\
\hline 5 & 8 & 7 & 8 & 7 & 3 & 2 \\
\hline 6 & 10 & 7 & 8 & 10 & 2 & 1 \\
\hline 7 & 10 & 10 & 8 & 8 & 7 & 4 \\
\hline 8 & 7 & 10 & 8 & 9 & 7 & 3 \\
\hline 9 & 9 & 4 & 7 & 6 & 3 & 2 \\
\hline 10 & 9 & 2 & 7 & 8 & 7 & 2 \\
\hline 11 & 10 & 10 & 10 & 10 & 5 & 2 \\
\hline 12 & 8 & 10 & 10 & 8 & 2 & 2 \\
\hline 13 & 10 & 10 & 8 & 10 & 7 & 4 \\
\hline 14 & 8 & 1 & 5 & 5 & 1 & 3 \\
\hline 15 & 9 & 8 & 6 & 7 & 5 & 2 \\
\hline 16 & 10 & 8 & 7 & 10 & 3 & 1 \\
\hline 17 & 9 & 9 & 7 & 9 & 3 & 5 \\
\hline 18 & 8 & 10 & 9 & 8 & 7 & 7 \\
\hline 19 & 8 & 3 & 5 & 5 & 3 & 1 \\
\hline 20 & 10 & 9 & 8 & 10 & 5 & 3 \\
\hline
\end{tabular}

On a scale of 1 to 10 , how much did you enjoy the experience? (20 Responses)

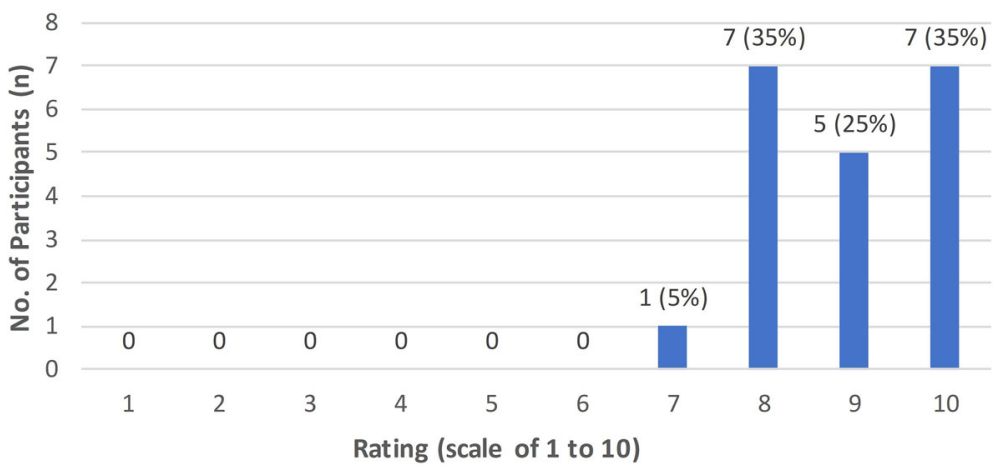

Fig. 4 Questionnaire results for Question 1 


\section{On a scale of 1 to 10, how surprised were you when you found that the game extended into the real world?(20 Responses)}

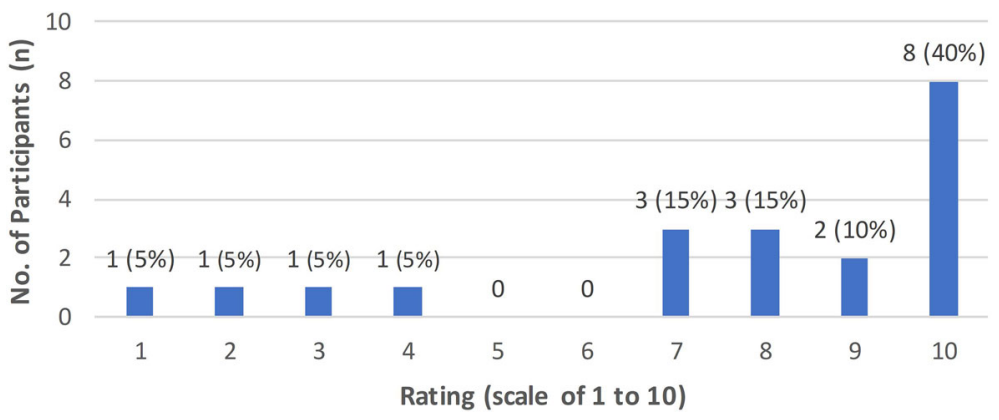

Fig. 5 Questionnaire results for Question 2

On a scale of 1 to 10 , how interactive did the game feel? (20 Responses)

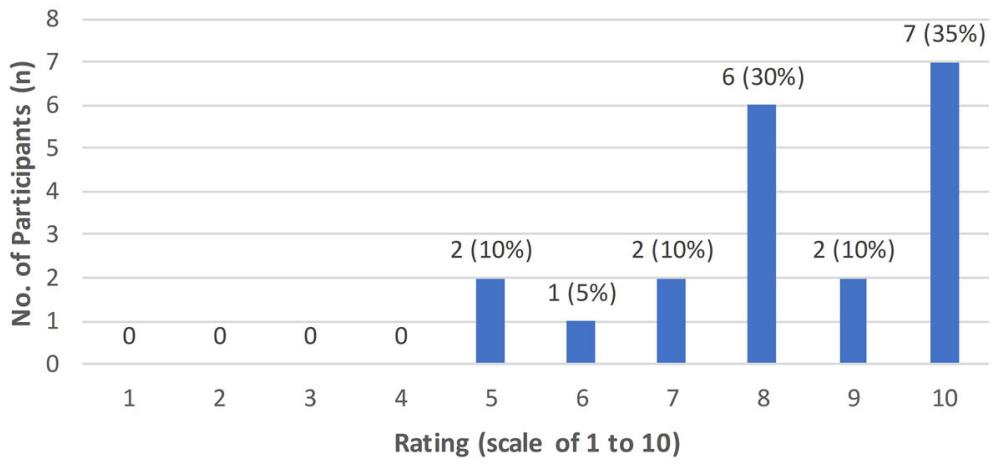

Fig. 6 Questionnaire results for Question 4

It might have been advisable to inform the participants about this in advance, although the sense of surprise would have been lost as a result. It should be mentioned again that the participants were permitted to withdraw from the case study at any point, but none of them did so; therefore, the invasive feelings they experienced were mild.

As also mentioned, at the end of the game the participants were presented with a bomb and were given an order to push a red button on the desk before it exploded. This was the only interaction where there was a time constraint; two participants commented on the sudden change of pace and the urgency of the situation:

There almost seemed like a sense of urgency though, so...it was good. (Participant 12). 
On a scale of 1 to 10 , how interactive did the game feel? (20 Responses)

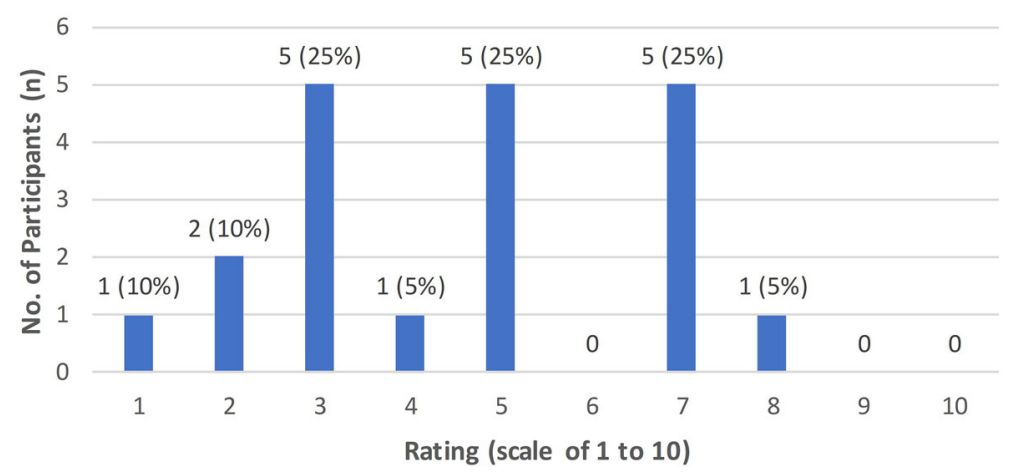

Fig. 7 Questionnaire results for Question 5

It was a bit of a change from the rest of the game, because the rest of the game felt quite relaxed. (Participant 6).

None of the participants said they did not enjoy the sudden change of pace, so it might be interesting to explore time limitations in future game installation projects.

Two of the participants complimented the game environment:

I think it was well done. It was very nice having physical things to do like entering the password. (Participant 14).

That was the best bit; you notice it when you sit down. Is this just a scruffy office, or is it part of the game? Then you realize it's part of the game. (Participant 3).

Some participants had difficulty identifying some of the interactable objects. According to Participant 15, "I'm just not very good at spotting things as with the book." Some suggested making the book interaction clearer rather than having it appear out of place. If more time had been available, a special book would have been prepared for the case study.

\subsubsection{References to Other Forms of Art}

Participants sometimes mentioned other art mediums or sources that could be of interest. One participant mentioned immersive theatre:

...It's quite similar to immersive theatre, in that respect where like you'd be in a room with an actor. So, instead of a voice-over, it could've potentially been that exact same scenario just with an actor. (Participant 19).

In future studies, it may be worth investigating the connections between game installations and immersive theatre. Three participants drew comparisons to virtual reality, including Participant 11: 
Table 4 Questionnaire results rearranged in order of data in answer to Question 1

\begin{tabular}{|c|c|c|c|c|c|c|}
\hline & $\begin{array}{l}\text { Q1: On a } \\
\text { scale of } 1 \text { to } \\
10, \text { how } \\
\text { much did } \\
\text { you enjoy } \\
\text { the } \\
\text { experience? }\end{array}$ & $\begin{array}{l}\text { Q2: On a scale of } \\
1 \text { to } 10 \text {, how } \\
\text { surprised were } \\
\text { you when you } \\
\text { found that the } \\
\text { game extended } \\
\text { into the real } \\
\text { world? }\end{array}$ & $\begin{array}{l}\text { Q3: On a } \\
\text { scale of } 1 \\
\text { to } 10 \text {, how } \\
\text { immersed } \\
\text { did you } \\
\text { find } \\
\text { yourself? }\end{array}$ & $\begin{array}{l}\text { Q4: On a } \\
\text { scale of } 1 \text { to } \\
10 \text {, how } \\
\text { interactive } \\
\text { do you think } \\
\text { the game } \\
\text { was? }\end{array}$ & $\begin{array}{l}\text { Q5: On a } \\
\text { scale of } 1 \\
\text { to } 10 \text {, how } \\
\text { difficult } \\
\text { did you } \\
\text { find the } \\
\text { game? }\end{array}$ & $\begin{array}{l}\text { Q6: On a } \\
\text { scale of } 1 \text { to } \\
10 \text {, how } \\
\text { stressful did } \\
\text { you find the } \\
\text { experience? }\end{array}$ \\
\hline \multicolumn{7}{|c|}{ Participant } \\
\hline 2 & 10 & 10 & 10 & 10 & 8 & 1 \\
\hline 7 & 10 & 10 & 8 & 8 & 7 & 4 \\
\hline 13 & 10 & 10 & 8 & 10 & 7 & 4 \\
\hline 11 & 10 & 10 & 10 & 10 & 5 & 2 \\
\hline 20 & 10 & 9 & 8 & 10 & 5 & 3 \\
\hline 16 & 10 & 8 & 7 & 10 & 3 & 1 \\
\hline 6 & 10 & 7 & 8 & 10 & 2 & 1 \\
\hline 10 & 9 & 2 & 7 & 8 & 7 & 2 \\
\hline 1 & 9 & 7 & 8 & 10 & 5 & 3 \\
\hline 15 & 9 & 8 & 6 & 7 & 5 & 2 \\
\hline 9 & 9 & 4 & 7 & 6 & 3 & 2 \\
\hline 17 & 9 & 9 & 7 & 9 & 3 & 5 \\
\hline 18 & 8 & 10 & 9 & 8 & 7 & 7 \\
\hline 3 & 8 & 10 & 9 & 8 & 5 & 3 \\
\hline 4 & 8 & 8 & 7 & 8 & 4 & 4 \\
\hline 5 & 8 & 7 & 8 & 7 & 3 & 2 \\
\hline 19 & 8 & 3 & 5 & 5 & 3 & 1 \\
\hline 12 & 8 & 10 & 10 & 8 & 2 & 2 \\
\hline 14 & 8 & 1 & 5 & 5 & 1 & 3 \\
\hline 8 & 7 & 10 & 8 & 9 & 7 & 3 \\
\hline
\end{tabular}

I've not ever tested virtual reality before, so that's [case study] probably the closest experience that I've had to that.

The types of interactions within typical VR games share similarities with those in this case study, which could be why participants identified this comparison.

Participant 2 said the game installation was akin to an ARG (Alternate-Reality Game), which is similar to locative media as the function of an ARG is to extend beyond the digital realm.

ARGs are focused on transmedia aspects. One popular example of an ARG is The Binding of Isaac where game modes were locked until it could be solved (Reddit 2014).

Participant 10 said that the game installation was similar to escape room experiences: 
Table 5 Questionnaire results rearranged in order of data in answer to Question 2

\begin{tabular}{|c|c|c|c|c|c|c|}
\hline & $\begin{array}{l}\text { Q1: On a } \\
\text { scale of } 1 \text { to } \\
10, \text { how } \\
\text { much did } \\
\text { you enjoy } \\
\text { the } \\
\text { experience? }\end{array}$ & $\begin{array}{l}\text { Q2: On a scale of } \\
1 \text { to } 10 \text {, how } \\
\text { surprised were } \\
\text { you when you } \\
\text { found that the } \\
\text { game extended } \\
\text { into the real } \\
\text { world? }\end{array}$ & $\begin{array}{l}\text { Q3: On a } \\
\text { scale of } 1 \\
\text { to } 10 \text {, how } \\
\text { immersed } \\
\text { did you } \\
\text { find } \\
\text { yourself? }\end{array}$ & $\begin{array}{l}\text { Q4: On a } \\
\text { scale of } 1 \text { to } \\
10 \text {, how } \\
\text { interactive } \\
\text { do you think } \\
\text { the game } \\
\text { was? }\end{array}$ & $\begin{array}{l}\text { Q5: On a } \\
\text { scale of } 1 \\
\text { to } 10 \text {, how } \\
\text { difficult } \\
\text { did you } \\
\text { find the } \\
\text { game? }\end{array}$ & $\begin{array}{l}\text { Q6: On a } \\
\text { scale of } 1 \text { to } \\
10, \text { how } \\
\text { stressful did } \\
\text { you find the } \\
\text { experience? }\end{array}$ \\
\hline \multicolumn{7}{|c|}{ Participant } \\
\hline 2 & 10 & 10 & 10 & 10 & 8 & 1 \\
\hline 7 & 10 & 10 & 8 & 8 & 7 & 4 \\
\hline 13 & 10 & 10 & 8 & 10 & 7 & 4 \\
\hline 18 & 8 & 10 & 9 & 8 & 7 & 7 \\
\hline 8 & 7 & 10 & 8 & 9 & 7 & 3 \\
\hline 11 & 10 & 10 & 10 & 10 & 5 & 2 \\
\hline 3 & 8 & 10 & 9 & 8 & 5 & 3 \\
\hline 12 & 8 & 10 & 10 & 8 & 2 & 2 \\
\hline 20 & 10 & 9 & 8 & 10 & 5 & 3 \\
\hline 17 & 9 & 9 & 7 & 9 & 3 & 5 \\
\hline 15 & 9 & 8 & 6 & 7 & 5 & 2 \\
\hline 4 & 8 & 8 & 7 & 8 & 4 & 4 \\
\hline 16 & 10 & 8 & 7 & 10 & 3 & 1 \\
\hline 1 & 9 & 7 & 8 & 10 & 5 & 3 \\
\hline 5 & 8 & 7 & 8 & 7 & 3 & 2 \\
\hline 6 & 10 & 7 & 8 & 10 & 2 & 1 \\
\hline 9 & 9 & 4 & 7 & 6 & 3 & 2 \\
\hline 19 & 8 & 3 & 5 & 5 & 3 & 1 \\
\hline 10 & 9 & 2 & 7 & 8 & 7 & 2 \\
\hline 14 & 8 & 1 & 5 & 5 & 1 & 3 \\
\hline
\end{tabular}

It was quite enjoyable actually, kind of like an escape room-type experience.

In escape room games, players have to solve puzzles or search around a room, which is identical to that in this case study. When designing the case study, inspiration was drawn from the best aspects of different game mediums and, judging by the above comments, it was evident that some participants could identify them.

\subsection{Questionnaire Analysis}

The questionnaire responses from all 20 participants were processed using MS Excel $^{\mathrm{TM}}$, and are provided in Table 3 below. The ratings in answer to questions 1, 2, 4 and 5 are also illustrated in Figs. 4, 5, 6 and 7. In general, most of the participants did not find the game overly stressful, although around a quarter of them found the 
Table 6 Questionnaire results rearranged in order of data for Question 2 and in order of data for Question 3

\begin{tabular}{|c|c|c|c|c|c|c|}
\hline & $\begin{array}{l}\text { Q1: On a } \\
\text { scale of } 1 \text { to } \\
10, \text { how } \\
\text { much did } \\
\text { you enjoy } \\
\text { the } \\
\text { experience? }\end{array}$ & $\begin{array}{l}\text { Q2: On a scale of } \\
1 \text { to } 10, \text { how } \\
\text { surprised were } \\
\text { you when you } \\
\text { found that the } \\
\text { game extended } \\
\text { into the real } \\
\text { world? }\end{array}$ & $\begin{array}{l}\text { Q3: On a } \\
\text { scale of } 1 \\
\text { to } 10 \text {, how } \\
\text { immersed } \\
\text { did you } \\
\text { find } \\
\text { yourself? }\end{array}$ & $\begin{array}{l}\text { Q4: On a } \\
\text { scale of } 1 \text { to } \\
10 \text {, how } \\
\text { interactive } \\
\text { do you think } \\
\text { the game } \\
\text { was? }\end{array}$ & $\begin{array}{l}\text { Q5: On a } \\
\text { scale of } 1 \\
\text { to } 10, \text { how } \\
\text { difficult } \\
\text { did you } \\
\text { find the } \\
\text { game? }\end{array}$ & $\begin{array}{l}\text { Q6: On a } \\
\text { scale of } 1 \text { to } \\
10, \text { how } \\
\text { stressful did } \\
\text { you find the } \\
\text { experience? }\end{array}$ \\
\hline \multicolumn{7}{|c|}{ Participant } \\
\hline 11 & 10 & 10 & 10 & 10 & 5 & 2 \\
\hline 2 & 10 & 10 & 10 & 10 & 8 & 1 \\
\hline 12 & 8 & 10 & 10 & 8 & 2 & 2 \\
\hline 18 & 8 & 10 & 9 & 8 & 7 & 7 \\
\hline 3 & 8 & 10 & 9 & 8 & 5 & 3 \\
\hline 13 & 10 & 10 & 8 & 10 & 7 & 4 \\
\hline 20 & 10 & 9 & 8 & 10 & 5 & 3 \\
\hline 1 & 9 & 7 & 8 & 10 & 5 & 3 \\
\hline 6 & 10 & 7 & 8 & 10 & 2 & 1 \\
\hline 8 & 7 & 10 & 8 & 9 & 7 & 3 \\
\hline 7 & 10 & 10 & 8 & 8 & 7 & 4 \\
\hline 5 & 8 & 7 & 8 & 7 & 3 & 2 \\
\hline 16 & 10 & 8 & 7 & 10 & 3 & 1 \\
\hline 17 & 9 & 9 & 7 & 9 & 3 & 5 \\
\hline 4 & 8 & 8 & 7 & 8 & 4 & 4 \\
\hline 10 & 9 & 2 & 7 & 8 & 7 & 2 \\
\hline 9 & 9 & 4 & 7 & 6 & 3 & 2 \\
\hline 15 & 9 & 8 & 6 & 7 & 5 & 2 \\
\hline 14 & 8 & 1 & 5 & 5 & 1 & 3 \\
\hline 19 & 8 & 3 & 5 & 5 & 3 & 1 \\
\hline
\end{tabular}

game quite difficult; however, most of them found it enjoyable and interactive, and felt immersed. Many of them were surprised to learn that the game extended into the real world, although a few other participants had probably anticipated this.

The results in the Excel spreadsheet were sorted in order to determine if there were any correlations among the data in the six columns. As shown in Table 4, the results were first rearranged in order of increasing enjoyment (Question 1). In general, those who found the game installation to be enjoyable also found the game interactive and felt surprised when they learned that the game extended into the real world. For Table 5, the data has been rearranged in order of increasing sense of surprise among the participants at having learned that the game extended into the real world: eight participants gave a 10/10 rating, and so had felt shocked by the news. In general, the more surprised they felt, the more immersive and interactive 
they found the game. For Table 6, the data was sorted firstly in order of the values for answers to Question 2 (surprise), and then in order of the values for answers to Question 5 (immersion): no obvious correlations can be seen between data in these columns and those in relation to questions 3 or 6 (level of difficulty or stress), and the relationship between the data in relation to questions 2 and 5 and the data in relation to question 4 (interactiveness of the game) is patchy.

\section{Conclusion}

Art installations, including digital-real world game installations, require direct observer participation and offer unique interactions. They range from being moderately interactive (e.g. GPS games) to high interactive (e.g. escape rooms), and can span both the digital and real worlds.

For this case study, a highly interactive game installation spanning both digital and real worlds was developed. It was tested by a sample of 20 participants, who were interviewed and who completed a questionnaire in order to determine the extents to which they found the game enjoyable, difficult, stressful, interactive and immersive; and also to gauge their reaction to finding out that the game, which started within the digital world, extended into the real world (in this case, set within an office on a university campus in Portsmouth, England).

Overall, the majority of participants felt satisfied and stimulated with the game installation, although some found the game difficult, and a few did not feel comfortable with being watched during the game testing session. Most of them were surprised to learn that the game extended beyond the digital world, although a few other participants had suspected that the game might involve performing actions in the real world.

Although most information collected in this case study is encouraging, this was only a case study, and further studies with larger groups of participants are required in order to confirm whether or not the game installation might be a popular and commercially viable concept.

Open Access This article is distributed under the terms of the Creative Commons Attribution 4.0 International License (http://creativecommons.org/licenses/by/4.0/), which permits unrestricted use, distribution, and reproduction in any medium, provided you give appropriate credit to the original author(s) and the source, provide a link to the Creative Commons license, and indicate if changes were made.

\section{References}

Bell, E. (2008). Theories of performance. Thousand Oaks: Sage.

Bricki, N. (2007). A guide to using qualitative research methodology. Paris: Medecins Sans Frontieres. Curious Escape. (2016) Curious Escape Rooms. Retrieved 30 September 2016. Website: http:// curiousescaperooms.com/.

Flanagan, M. (2009). Critical play: Radical game design. Cambridge: MIT Press.

Flintham, M. (2012). Mixed reality games. Retrieved 30 September 2016. Website: http://www.cs.nott.ac. $\mathrm{uk} /$ pszmw/G54MXR/g54mxr-13-martin.pdf.

Frayling, C. (1994). Research in art and design. Royal College of Art Research Papers. 
Galloway, A., \& Ward, M. (2007). Locative media as socialising and spatializing practices: Learning from archaeology. Cambridge: MIT Press.

Johnson, J. (2014). This Demented Macbook is Only Happy if You Shoot Yourself in the Head. Retrieved: 5 October 2016. Website: https://killscreen.com/articles/demented-macbook-only-happy-if-youshoot-yourself-head/.

Konami Computer Entertainment. (1998). Metal Gear Solid. [Video Game] Tokyo: Konami.

Kusama. (2015). The Obliteration Room. Retrieved 5 October 2016. Website: http://interactive.qag.qld. gov.au/looknowseeforever/works/obliteration_room/.

Lunenfield, P. (2003). “The Design Cluster” The Intelligent Agent. Retrieved 28 June 2017. Website: www.intelligentagent.com/ME/Lunenfeld.pdf.

Magruder, M. (2014). De/coding the Apocalypse. Retrieved 15 December 2016. Website: http://www. takeo.org/nspace/2014-decoding-the-apocalypse/

Microsoft. (2014). RoomAlive.

Lunenfield, P. (2003). “The Design Cluster" The Intelligent Agent. Retrieved 28 June 2017. Website: www.intelligentagent.com/ME/Lunenfeld.pdf.

Magruder, M. (2014). De/coding the Apocalypse. Retrieved 15 December 2016. Website: http://www. takeo.org/nspace/2014-decoding-the-apocalypse/

Microsoft. (2014). RoomAlive.

Niantic. (2016). Pokémon Go. [Video Game] San Francisco: Niantic.

Nintendo IRD. (1990). Star Tropics. [Video Game] Kyoto: Nintendo.

Ow, C. (2011). Plane White. Retrieved 15 December 2016. Website: http://www.carinaow.com/2011/06/ 01/plane-white/.

Paul, C. (2015). Digital Art (World of Art). Thames \& Hudson.

Romero, B. (2009) Train. Retrieved 30 September 2016. Website: http://www.blromero.com/train/.

Reddit. (2014). "How to Install and Run Antibirth - a Comprehensive Guide" The Binding of Issac Reddit+ Retrieved 28 June 2017. Website: https://www.reddit.com/r/bindingofisaac/comments/ 5jhuhb/how_to_install_and_run_antibirth_a_comprehensive/.

Silicon Knights. (2002). Eternal Darkness: Sanity's Requiem. [Video Game] Kyoto: Nintendo.

Symons, S. (2004). Aura: the Stuff Around the Stuff Around You. Retrieved 30 September 2016. Website: http://stevesymons.net/aura1.

Saatchi Gallery. (2016). Tracey Emin - My Bed. Retrieved 5 October 2016. Website: http://www. saatchigallery.com/artists/artpages/tracey_emin_my_bed.htm.

Tate Modern. (2016). Installation Art. Retrieved: 26 October 2016. Website: http://www.tate.org.uk/ learn/online-resources/glossary/i/installation-art.

Thom, D. (2014). "Are Art Installations the New Video Games?" Apollo Magazine, 14 August 2014. Retrieved 28 June 2017. Website: https://www.apollo-magazine.com/art-installations-new-videogames/.

Wrenden, D. (2013). The Stanley Parable Creator Davey Wreden Discusses His Un-Discussable Game. Retrieved 27 February 2015. Website: http://killscreendaily.com/articles/articles/inside-stanleyparable-game-no-one-can-describe/.

\section{Ludology}

Konami Computer Entertainment. (1998) Metal Gear Solid. [Video Game] Tokyo: Konami.

Magruder, M. (2014) De/coding the Apocalypse. Retrieved 15 December 2016. Website: http://www. takeo.org/nspace/2014-decoding-the-apocalypse/.

Microsoft (2014). RoomAlive.

Niantic. (2016) Pokémon Go. [Video Game] San Francisco: Niantic.

Nintendo IRD. (1990) Star Tropics. [Video Game] Kyoto: Nintendo.

Ow, C. (2011) Plane White. Retrieved 15 December 2016. Website: http://www.carinaow.com/2011/06/ 01/plane-white/

Romero, B. (2009) Train. Retrieved 30 September 2016. Website: http://www.blromero.com/train/ Silicon Knights. (2002) Eternal Darkness: Sanity's Requiem. [Video Game] Kyoto: Nintendo.

Symons, S. (2004) Aura: the Stuff Around the Stuff Around You. Retrieved 30 September 2016. Website: http://stevesymons.net/aura1 